\title{
Tandem C-O and C-H Activation at Palladium Enables Catalytic Direct C-H Alkenylation with Enol Pivalates
}

\author{
Nahiane Pipaon Fernandez, Gregory Gaube, Kyla J. Woelk, Mathias Burns, and David C. Leitch* \\ Department of Chemistry, University of Victoria, 3800 Finnerty Rd., Victoria, BC V8P 5C2 (Canada) \\ *dcleitch@uvic.ca
}

\begin{abstract}
The use of oxygen-based electrophiles in cross-coupling remains challenging for substrates with strong $\mathrm{C}-\mathrm{O}$ bonds, with few examples that can combine $\mathrm{C}-\mathrm{O}$ activation with another strong-bond activation in tandem. We report the first example of a direct, tandem $\mathrm{C}-\mathrm{O} / \mathrm{C}-\mathrm{H}$ activation approach to $\mathrm{C}-\mathrm{C}$ bond formation using palladium catalysis. This reaction combines $\mathrm{C}-\mathrm{O}$ oxidative addition at enol pivalates with concerted metallation deprotonation of functionalized heterocycles to achieve base-free direct $\mathrm{C}-\mathrm{H}$ alkenylation, with pivalic acid as the only byproduct. Mechanistic studies reveal that the Pd(II) $\mathrm{C}-\mathrm{O}$ oxidative addition product is the major catalyst resting state, indicating that $\mathrm{C}-\mathrm{H}$ activation is the turnover-limiting step.
\end{abstract}

The selective activation and functionalization of strong carbon-element bonds is one of the primary challenges in developing new methods for organic synthesis. The ability to transform ubiquitous $\mathrm{C}-\mathrm{H}, \mathrm{C}-\mathrm{O}$, or other strong bonds into more complex molecular structures often represents a more direct approach to access target molecules. This results in fewer synthetic steps and greater mass efficiency in the overall process, as well as unlocking new feedstocks and building blocks as substrates. ${ }^{1,2}$ Accordingly, considerable effort has been devoted to incorporating $\mathrm{C}-\mathrm{H}^{3-11}$ or $\mathrm{C}-$ $\mathrm{O}^{12-21}$ bond activation in redox-neutral cross-coupling catalysis. Far less developed are catalytic processes that combine multiple strong bond activations into a single transformation. ${ }^{22}$

Tandem $\mathrm{C}-\mathrm{O} / \mathrm{C}-\mathrm{H}$ activation to form new $\mathrm{C}-\mathrm{C}$ bonds is a particularly attractive yet challenging approach to cross-coupling (Figure 1a). One approach is to take advantage of $\mathrm{C}_{\text {acyl}}-\mathrm{O}$ activation of activated carboxylic acid derivatives, followed by decarbonylation of the resulting metal-acyl intermediate. ${ }^{18} \mathrm{Rh}$ catalysis involving directing-group assisted $\mathrm{C}-\mathrm{H}$ activation is the major reported method. ${ }^{23-30}$ For reactions without $\mathrm{C}-\mathrm{H}$ directing groups, $\mathrm{Ni}$ catalysis ${ }^{31}$ and more recently tandem $\mathrm{Pd} / \mathrm{Cu}$ catalysis ${ }^{32,33}$ have been reported. A more direct method is tandem $\mathrm{C}-\mathrm{O} / \mathrm{C}-\mathrm{H}$ activation involving ester, ether, or carbamate leaving groups. The major challenge is that this requires activating a considerably stronger C-O bond..$^{12}$ Itami and co-workers first demonstrated this approach with $\mathrm{Ni}$-catalysis to couple aryl pivalates with azoles; ${ }^{34}$ subsequent studies further explored the synthetic and mechanistic aspects of this catalysis. ${ }^{35-38}$ Song and Ackermann contemporaneously reported a Co-system for directed $\mathrm{C}-\mathrm{H}$ arylation with carbamate substrates. ${ }^{39}$ Since these initial reports, only a few additional direct $\mathrm{C}-\mathrm{O} / \mathrm{C}-\mathrm{H}$ coupling methods have appeared: Shi and co-workers disclosed a dual $\mathrm{Ni} / \mathrm{Cu}$ system for perfluoroarene $\mathrm{C}-\mathrm{H}$ functionalization with aryl carbamates; ${ }^{40} \mathrm{Zhao}$, Ong and co- workers reported a Ni-based coupling of aryl ethers with imidazoles; ${ }^{41}$ and Toupalas and Morandi recently reported an example of $\mathrm{Ni}$-catalyzed coupling between an aryl carbamate and benzoxazole. ${ }^{42}$ Notably, despite the success of Pd catalysis for direct arylation using (pseudo)halide electrophiles, ${ }^{43}$ no Pd systems for direct $\mathrm{C}-\mathrm{O} / \mathrm{C}-\mathrm{H}$ coupling have been reported. This is perhaps due to the perception that $\mathrm{Pd}$ catalysts cannot perform the required C-O activation to engage aryl or enol ester substrates. ${ }^{16,20}$

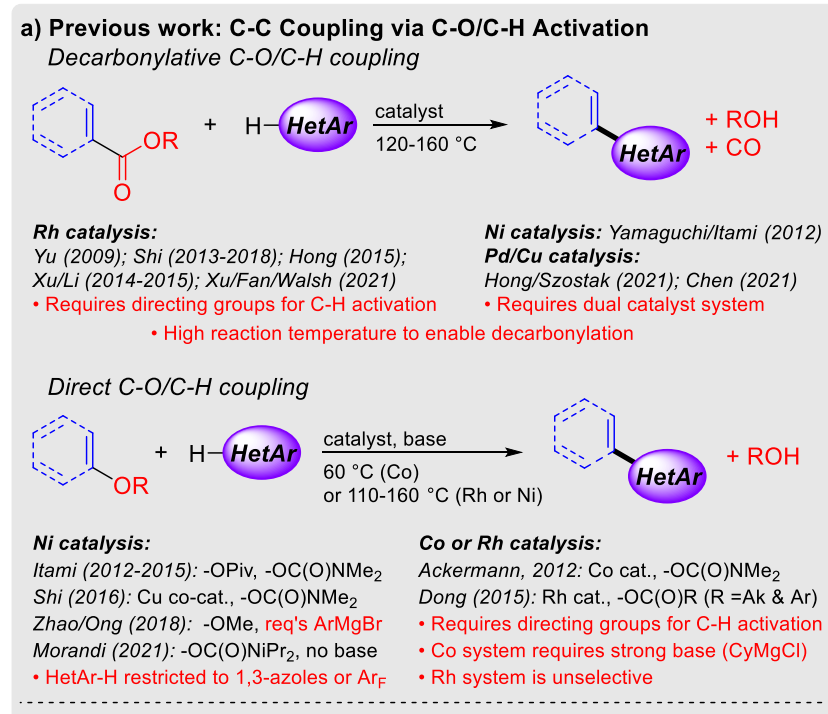

b) This work: Pd-catalyzed direct $\mathrm{C}-\mathrm{H}$ alkenylation with enol pivalates

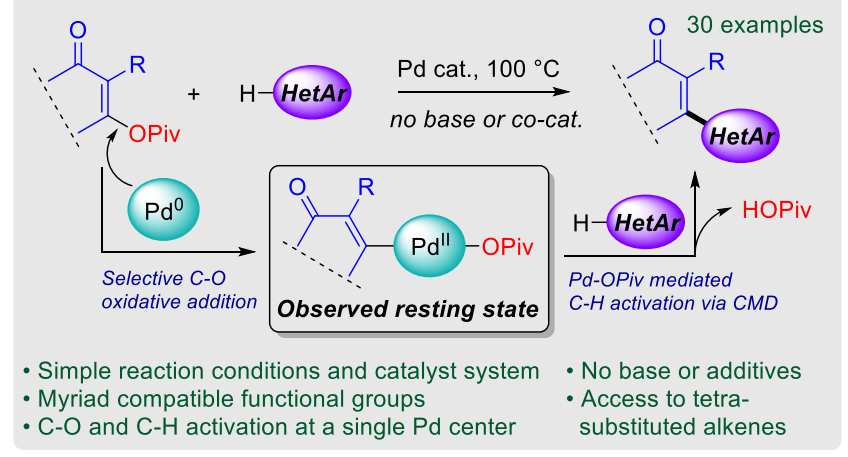

Figure 1. a) Catalytic $\mathrm{C}-\mathrm{O} / \mathrm{C}-\mathrm{H}$ coupling, based on decarbonylative or direct $\mathrm{C}-\mathrm{C}$ formation. b) Pd-catalyzed direct $\mathrm{C}-\mathrm{O} / \mathrm{C}-\mathrm{H}$ coupling via selective $\mathrm{C}-\mathrm{O}$ activation and subsequent concerted metallation deprotonation (CMD). 
Here, we report a palladium-catalyzed tandem $\mathrm{C}-\mathrm{O} / \mathrm{C}-\mathrm{H}$ activation process for the direct alkenylation of a variety of aromatic heterocycles using enol pivalates (Figure 1b). In contrast to nearly all of the aforementioned methods, this coupling proceeds without the need for bases, additives, or co-catalysts. This is possible because of the direct formation of the key $\mathrm{Pd}(\mathrm{II})$ pivalate intermediate via $\mathrm{C}-\mathrm{O}$ oxidative addition, which then activates the $\mathrm{Het} \mathrm{Ar}-\mathrm{H}$ bond via concerted metallation deprotonation (CMD); ${ }^{44}$ in other words, no exogenous base or carboxylic acid additive is required to convert the $\mathrm{Pd}(\mathrm{II})$ halide intermediate into a $\mathrm{Pd}(\mathrm{II})$ carboxylate, nor to quench the pivalic acid byproduct (Figure 1c). Mechanistic studies confirm that this proposed sequence of steps is viable, with direct observation of the $\mathrm{Pd}(\mathrm{II})$ pivalate species as the major catalyst resting state.

Our group has recently reported that alkenyl carboxylates undergo $\mathrm{C}-\mathrm{O}$ oxidative addition to $\mathrm{Pd}(0)$ complexes, ${ }^{45}$ and that base-free catalytic Suzuki cross-coupling ${ }^{46}$ and Miyaura borylation $^{[47]}$ are possible with these substrates. A major challenge in Suzuki coupling is the use of heterocycles as nucleophiles: installing boronic acids or boronate esters on the carbon $\alpha$ to heteroatoms is synthetically challenging; the resulting products are often not stable; and protodeborylation during catalysis is a significant side reaction. ${ }^{47}$ To explore the possibility of $\mathrm{Pd}$-catalyzed heterocycle $\mathrm{C}-\mathrm{H}$ alkenylation using enol ester substrates, we designed a series of multivariate high-throughput screening experiments ${ }^{48-51}$ for the $\mathrm{C}-\mathrm{H}$ alkenylation of benzothiophene (2a) with a dimedone-derived enol pivalate (1a) (Figure 2).

An initial 24-reaction screen was designed to discover potential Pd catalysts for this transformation (Figure 2a). In situ catalyst formation was achieved using a set of six phosphines and four $\mathrm{Pd}$ sources. In addition to standard $\mathrm{Pd}(\mathrm{II})$ and $\mathrm{Pd}(0)$ compounds $-\mathrm{Pd}(\mathrm{OAc})_{2},[\mathrm{Pd}(\mathrm{allyl}) \mathrm{Cl}]_{2}$, and freshly prepared and recrystallized $\mathrm{Pd}_{2} \mathrm{dba}_{3} \cdot \mathrm{CHCl}_{3}{ }^{52}$ - we included our recently reported precatalyst $\mathrm{DAB}-\mathrm{Pd}-\mathrm{MAH}$ as an alternate $\mathrm{Pd}(0)$ source that is highly effective for microscale screening experiments. ${ }^{53}$ The six phosphines were chosen based on their known utility for Pd-catalyzed direct arylation. $3,43,54,55 \mathrm{~N}, \mathrm{~N}$-dimethylacetamide (DMA) was fixed as the solvent based also on prior precedent, ${ }^{43}$ and $N, N$ diisopropylethylamine (DIPEA) was added to quench the equivalent of pivalic acid generated from the coupling. Among the $\mathrm{Pd} /$ ligand combinations screened, only $\mathrm{PC}_{3}$ paired with $\mathrm{Pd}(\mathrm{OAc})_{2}$ or $\mathrm{DAB}-\mathrm{Pd}-\mathrm{MAH}$ enabled product formation, with the latter $\mathrm{Pd}$ source giving $34 \%$ solution yield of $\mathbf{3 a}$ (HPLC UV/Vis absorbance versus calibration curve).

Using DAB-Pd-MAH as the Pd source, we then designed a more extensive 108-reaction screen to evaluate the combination of ligand (18 phosphines), solvent (DMA and cyclopentylmethyl ether - CPME), and base (DIPEA, 1,8-diazabicyclo[5.4.0]undec7-ene - DBU - and no base). Due to the relatively low reactivity observed in the initial screen, we increased the catalyst loading to $24 \mathrm{~mol} \%$ (Figure 2b). Across these conditions, $\mathrm{PCy}_{3}$ again emerged as the only effective ligand, giving $33-40 \%$ solution yield of $3 \mathbf{a}$ with DMA and either DIPEA or no added base. The nextbest result is a $10 \%$ solution yield of $3 a$ using $\mathrm{PMe}(t-\mathrm{Bu})_{2}$ in CPME with DBU as the base. a)
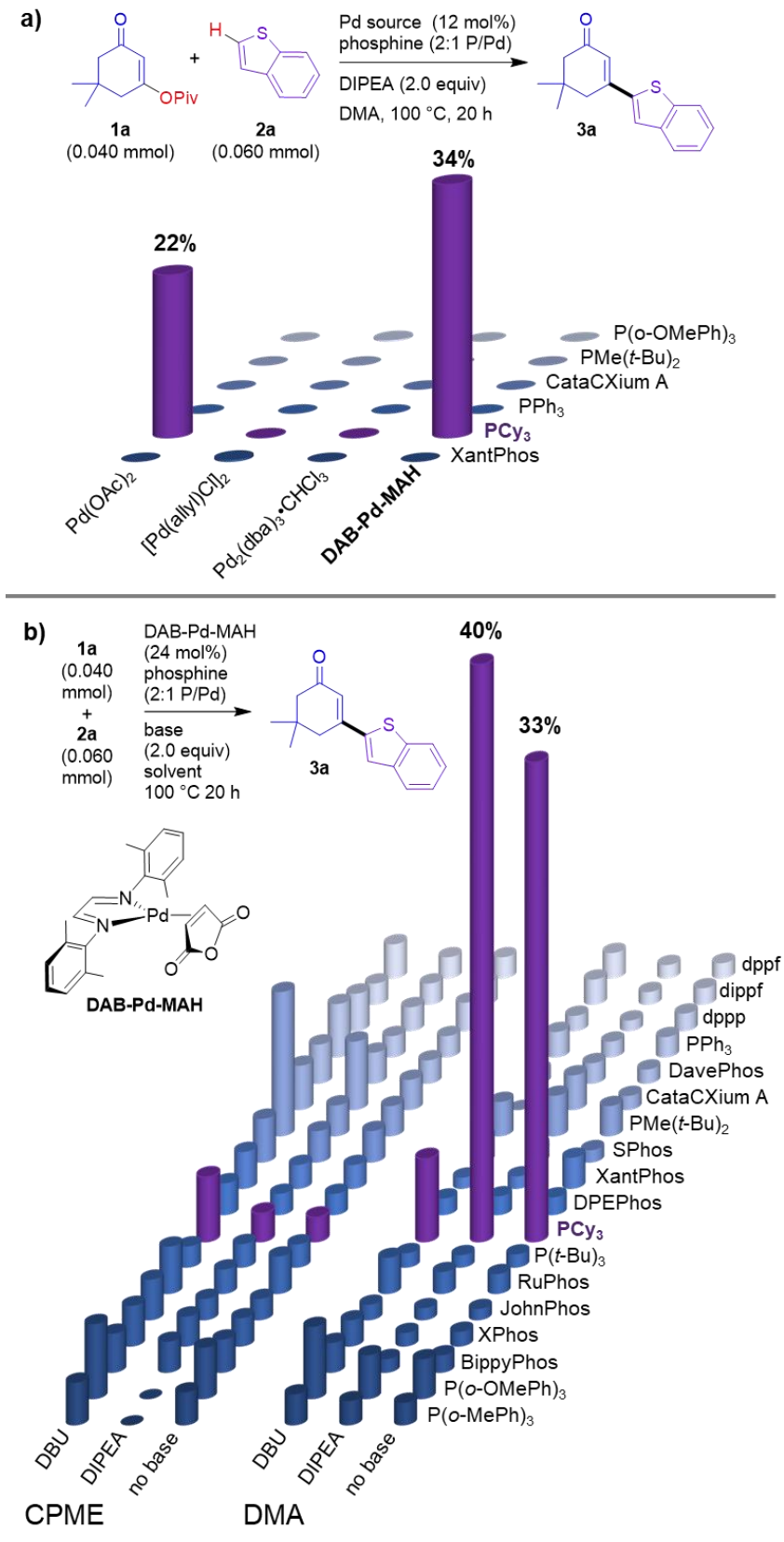

c)

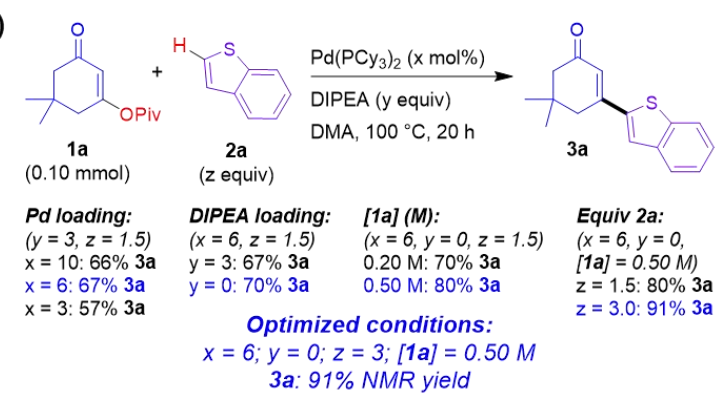

Figure 2. Reaction discovery and optimization for Pd-catalyzed tandem $\mathrm{C}-\mathrm{O} / \mathrm{C}-\mathrm{H}$ coupling. a) Initial catalyst screen. b) Extensive ligand survey using DAB-Pd-MAH and multiple base/solvent combinations. c) Targeted optimization. Yields for $\mathbf{a}$ ) and $\mathbf{b}$ ) determined by HPLC UV/Vis absorbance using a calibration curve for $\mathbf{3 a}$; yields for $\mathbf{c}$ ) determined by ${ }^{1} \mathrm{H}$ NMR spectroscopy versus internal standard (1,3,5-trimethoxybenzene). 


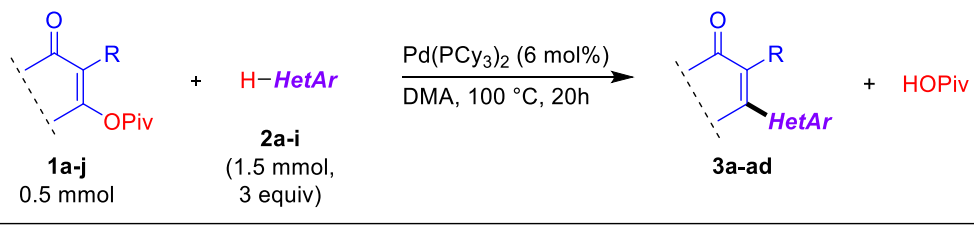

(3a, 86\%)<smiles>Cc1nc(-c2ccccc2)c(C2=CC(=O)CC(C)(C)C2)s1</smiles><smiles>CC1(C)CC(=O)C=C(c2sc(-c3cccnc3)nc2-c2ccccc2)C1</smiles>
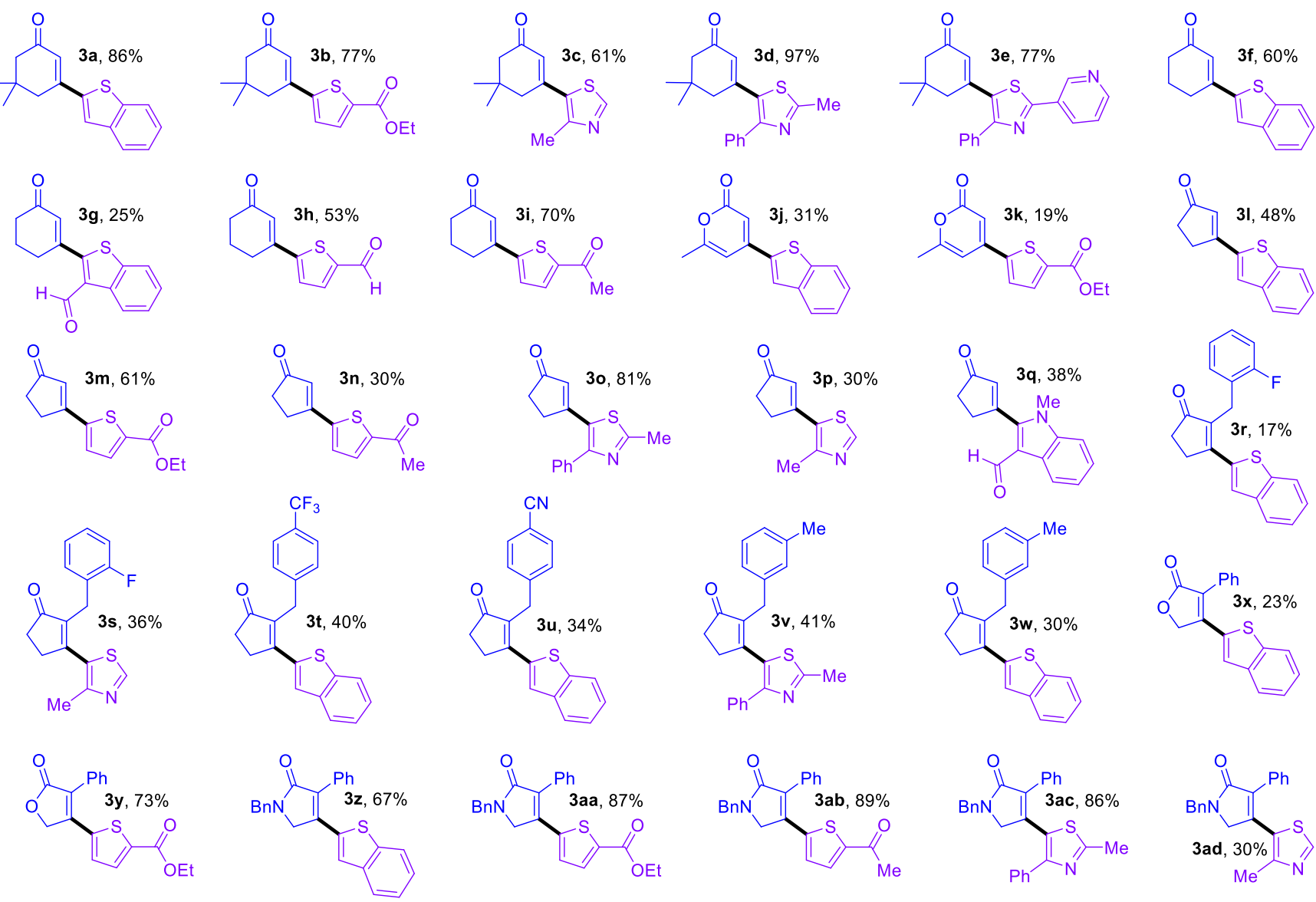

Figure 3. Reaction scope of the Pd-catalyzed direct arylation of alkenyl pivalates, with isolated product yields obtained after purification by flash chromatography.

To improve catalyst activity for a $\mathrm{PCy}_{3}$-based system, we considered that the presence of stabilizing ligands in the DAB-Pd$\mathrm{MAH}$ precursor could be inhibiting the $\mathrm{C}-\mathrm{O}$ oxidative addition. Based on our prior success with $\mathrm{Pd}\left(\mathrm{PCy}_{3}\right)_{2}$ as a single-component catalyst for coupling with $\mathrm{C}-\mathrm{O}$ electrophiles, ${ }^{46,56}$ we evaluated this $\mathrm{Pd}(0)$ source for the coupling of $\mathbf{1 a}$ and $\mathbf{2 a}$ on $0.10 \mathrm{mmol}$ scale. At a reduced catalyst load of $10 \mathrm{~mol} \% \mathrm{Pd}$, we observe a $66 \%$ solution yield of $\mathbf{3 a}\left({ }^{1} \mathrm{H}\right.$ NMR spectroscopy versus internal standard). We then conducted a targeted optimization of Pd loading, base, concentration, and stoichiometry (Figure $2 \mathrm{c}$ ). This study revealed that $6 \mathrm{~mol} \% \mathrm{Pd}$ performs similarly to $10 \mathrm{~mol} \%$ over the 20 $\mathrm{h}$ reaction time, the addition of DIPEA has no effect on the reaction outcome, and a higher overall reaction concentration $(0.50 \mathrm{M}$ in 1a) combined with an increased loading of heterocycle (3 equiv) results in $91 \%$ solution yield of $\mathbf{3 a}$.

With effective reaction conditions identified, we sought to evaluate the reactivity of varied enol pivalates and heterocycles in this tandem $\mathrm{C}-\mathrm{O} / \mathrm{C}-\mathrm{H}$ activation process (Figure 3 ). Preparative scale synthesis of 3 a proceeded in $86 \%$ isolated yield. A series of other heterocycles also performed well in combination with 1a, including sterically-hindered thiazoles (3b-e). Other thiophene derivatives with potentially reactive aldehyde and ketone functional groups undergo coupling to an unsubstituted cyclohexenyl pivalate substrate (3f-i). A pyrone-derived pivalate is compatible, though modest yields are obtained (3j-k). Cyclopentenone products are accessible using this methodology through $\mathrm{C}-\mathrm{H}$ functionalization of thiophene and thiazole heterocycles (3I-p), as well as 1-methyl-3-formylindole (3q). Initial attempts to perform coupling using 2-substituted cyclohexenone derivatives led to no observable reaction; however, 2-alkylcyclopentenone substrates can be successfully arylated $(\mathbf{3 r}-\mathbf{w})$. While the yields are modest, crosscoupling to form tetrasubstituted alkenes is known to be challenging. ${ }^{57,58}$ Finally, $y$-lactone $(\mathbf{3 x}-\mathbf{y})$ and $y$-lactam (3z-ad) substrates are successfully arylated, generating multisubstituted $\alpha, \beta$-unsaturated $\gamma$-lactone and $\gamma$-lactam compounds. Notably, many biologically active compounds include $y$-lactone and $y$-lactam units, including natural products, ${ }^{59,60}$ synthetic pesticides, ${ }^{61}$ and COX-2 inhibitors. ${ }^{62}$ Overall, myriad potentially sensitive and/or deactivating groups are compatible, including aldehyde, ketone, ester, amide, nitrile, pyridine, thiophene, thiazole, and indole. 

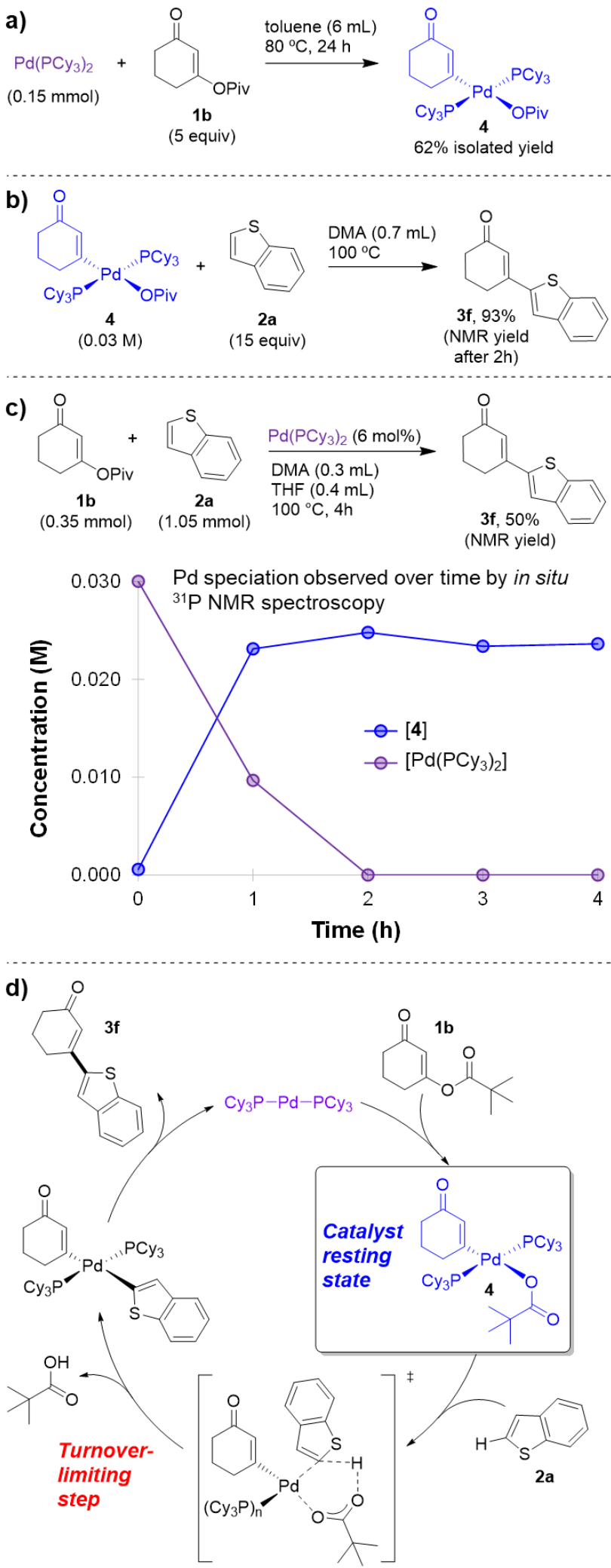

Figure 4. Mechanistic studies of the tandem $\mathrm{C}-\mathrm{O} / \mathrm{C}-\mathrm{H}$ sequence. a) Oxidative addition of $\mathbf{1 b}$ to $\mathrm{Pd}\left(\mathrm{PCy}_{3}\right)_{2}$ to generate $\mathbf{4}$ in $62 \%$ isolated yield. b) $\mathrm{C}-\mathrm{H}$ activation of $\mathbf{2 a}$ and reductive elimination to form $\mathbf{3 f}(93 \%$ NMR yield) is viable from compound 4. c) Monitoring Pd speciation during catalysis by in situ ${ }^{31} \mathrm{P}$ NMR spectroscopy, with oxidative addition complex $\mathbf{4}$ as the major observed species (concentration determined by relative integration to $\mathrm{PPh}_{3}$ standard contained inside a sealed capillary tube). d) Proposed reaction mechanism, with CMD as the turnover-limiting step based on $\mathbf{4}$ as the observed resting state during catalysis.
Based on the promising reactivity observed in this coupling chemistry, we sought to further understand the catalytic mechanism through a series of preliminary mechanistic experiments (Figure 4). We first performed the oxidative addition of pivalate $\mathbf{1 b}$ to $\mathrm{Pd}(\mathrm{PCy})_{2}$ to generate the putative intermediate 4 . By analogy to previous work from our laboratory, ${ }^{45}$ we successfully prepared and isolated complex $\mathbf{4}$ in $62 \%$ yield (Figure 4a). Compound $\mathbf{4}$ was fully characterized by solution and mass spectrometric methods, confirming the structure as the monomeric bis(phosphine) rather than a mono(phosphine) carboxylate-bridged dimer.

To test the possible intermediacy of $\mathbf{4}$ in the catalytic $\mathrm{C}-\mathrm{H}$ alkenylation reaction, we assessed the ability of isolated $\mathbf{4}$ to promote $\mathrm{C}-\mathrm{H}$ activation of benzothiophene $\mathbf{2 a}$ (Figure $4 \mathrm{~b}$ ). After heating 4 with excess $2 a$ in DMA for 2 hours at $100^{\circ} \mathrm{C}$, we observe complete consumption of 4 by ${ }^{31} \mathrm{P}$ NMR spectroscopy. Subsequent aqueous workup and extraction with TBME confirmed the organic product is $\mathbf{3 f}$, generated in $93 \%$ solution yield (versus 1,3,5-trimethoxybenzene as internal standard).

Given the viable intermediacy of $\mathbf{4}$ in the tandem $\mathrm{C}-\mathrm{O} / \mathrm{C}-\mathrm{H}$ activation process, we sought to confirm its presence during catalysis. Performing the coupling of $\mathbf{1 b}$ and $\mathbf{2} \mathbf{a}$ in a DMA/THF solvent mixture led to complete dissolution of $\mathrm{Pd}\left(\mathrm{PCy}_{3}\right)_{2}$ at room temperature, enabling accurate ${ }^{31} \mathrm{P}$ NMR spectroscopic analysis at time zero. Upon heating the reaction mixture to $100^{\circ} \mathrm{C}$ in $1 \mathrm{~h}$ intervals, ${ }^{31} \mathrm{P}$ NMR spectroscopy reveals that 4 is the major ${ }^{31} \mathrm{P}$ containing species in solution, with a steady concentration over $4 \mathrm{~h}$, over which time the coupling reaction proceeds to $50 \%$ yield (Figure 4c).

Taken together, these observations are consistent with the mechanistic proposal in Figure $4 d$, where $\mathrm{Pd}\left(\mathrm{PCy}_{3}\right)_{2}$ first undergoes oxidative addition of the enol pivalate $\mathrm{C}-\mathrm{O}$ bond to generate 4. Despite the fact that $\mathrm{C}-\mathrm{O}$ oxidative addition is generally difficult to achieve at $\mathrm{Pd}(0)$, complex $\mathbf{4}$ is observed as the major catalytic resting state. Subsequent turnover-limiting $\mathrm{C}-\mathrm{H}$ metallation then occurs via CMD, taking advantage of the already-installed pivalate ligand. This is followed by rapid reductive elimination to form the cross-coupled product and regenerate $\mathrm{Pd}\left(\mathrm{PCy}_{3}\right)_{2}$. While $\mathrm{C}-\mathrm{H}$ activation is observed to be turnover-limiting in the coupling of $\mathbf{1 b}$ and $\mathbf{2 a}$, the relative rates of $\mathrm{C}-\mathrm{O}$ and $\mathrm{C}-\mathrm{H}$ activation may change significantly for other substrate combinations. Further work is underway to take advantage of the mechanistic tractability of this system to completely map the structure-reactivity profiles of these two steps for a variety of substrates.

In summary, we have developed the first Pd-catalyzed direct $\mathrm{C}-\mathrm{O} / \mathrm{C}-\mathrm{H}$ coupling reaction, enabling the $\mathrm{C}-\mathrm{H}$ alkenylation of heterocycles without the need for directing groups, co-catalysts, additives, oxidants, or any other reagents. The chemistry is compatible with many potentially sensitive functional groups, allowing access to functionalized enones, pyrones, lactones, and lactams. By taking advantage of $\mathrm{C}-\mathrm{O}$ oxidative addition of enol pivalates to $\mathrm{Pd}(0)$, the carboxylate ligand required for $\mathrm{C}-\mathrm{H}$ activation via $\mathrm{CMD}$ is directly installated, removing the need for exogenous base or carboxylic acid additives. Based on the observation of the C-O oxidative addition complex $\mathbf{4}$ as the major catalyst resting state, CMD is turnover-limiting in this system. We are currently exploring both the synthetic and mechanistic implications of this work, which will open the door to efficient catalytic $\mathrm{C}-\mathrm{H}$ functionalization from entirely new feedstocks and building blocks. 


\section{Acknowledgements}

We acknowledge with respect the Lekwungen peoples, on whose traditional territory the University of Victoria (UVic) stands, and the Songhees, Esquimalt, and WSÁNEĆ peoples whose historical relationships with the land continue to this day. We also thank GlaxoSmithKline Inc., Mitacs (RTA to GG), NSERC (CGS-M to KJW, Discovery and Alliance Grants to DCL), CFI, and BCKDF for operating and equipment funds.

\section{References}

(1) Qiu, Z.; Zeng, H.; Li, C.-J. Coupling without Coupling Reactions: En Route to Developing Phenols as Sustainable Coupling Partners via Dearomatization-Rearomatization Processes. Acc. Chem. Res. 2020, 53, 2395-2413. https://doi.org/10.1021/acs.accounts.0c00479.

(2) Dalton, T.; Faber, T.; Glorius, F. C-H Activation: Toward Sustainability and Applications. ACS Cent. Sci. 2021, 7, 245-261. https://doi.org/10.1021/acscentsci.0c01413.

(3) Alberico, D.; Scott, M. E.; Lautens, M. Aryl-Aryl Bond Formation by Transition-Metal-Catalyzed Direct Arylation. Chem. Rev. 2007, 107, 174-238. https://doi.org/10.1021/cr0509760.

(4) Chen, X.; Engle, K. M.; Wang, D.-H.; Yu, J.-Q. Palladium(II)-Catalyzed C-H Activation/C-C Cross-Coupling Reactions: Versatility and Practicality. Angew. Chem. Int. Ed. 2009, 48, 5094-5115. https://doi.org/10.1002/anie.200806273.

(5) Wencel-Delord, J.; Dröge, T.; Liu, F.; Glorius, F. Towards Mild MetalCatalyzed C-H Bond Activation. Chem. Soc. Rev. 2011, 40, 4740-4761. https://doi.org/10.1039/C1CS15083A.

(6) Engle, K. M.; Mei, T.-S.; Wasa, M.; Yu, J.-Q. Weak Coordination as a Powerful Means for Developing Broadly Useful C-H Functionalization Reactions. Acc. Chem. Res. 2012, 45, 788-802. https://doi.org/10.1021/ar200185g.

(7) Gorelsky, S. I. Origins of Regioselectivity of the Palladium-Catalyzed (Aromatic) CH Bond Metalation-Deprotonation. Coord. Chem. Rev. 2013, 257, 153-164. https://doi.org/10.1016/j.ccr.2012.06.016.

(8) Giri, R.; Thapa, S.; Kafle, A. Palladium-Catalysed, Directed C-H Coupling with Organometallics. Adv. Synth. Catal. 2014, 356, 1395-1411. https://doi.org/10.1002/adsc.201400105.

(9) Gensch, T.; Hopkinson, M. N.; Glorius, F.; Wencel-Delord, J. Mild MetalCatalyzed C-H Activation: Examples and Concepts. Chem. Soc. Rev. 2016, 45, 2900-2936. https://doi.org/10.1039/C6CS00075D.

(10) Rogge, T.; Kaplaneris, N.; Chatani, N.; Kim, J.; Chang, S.; Punji, B.; Schafer, L. L.; Musaev, D. G.; Wencel-Delord, J.; Roberts, C. A.; Sarpong, R.; Wilson, Z. E.; Brimble, M. A.; Johansson, M. J.; Ackermann, L. C-H Activation. Nature Rev. Methods Primers 2021, 1, 43. https://doi.org/10.1038/s43586-021-00041-2.

(11) Carrow, B. P.; Sampson, J.; Wang, L. Base-Assisted C-H Bond Cleavage in Cross-Coupling: Recent Insights into Mechanism, Speciation, and Cooperativity. Isr. J. Chem. 2020, 60, 230-258. https://doi.org/10.1002/ijch.201900095.

(12) Yu, D.-G.; Li, B.-J.; Shi, Z.-J. Exploration of New C-O Electrophiles in Cross-Coupling Reactions. Acc. Chem. Res. 2010, 43, 1486-1495. https://doi.org/10.1021/ar100082d.

(13) Rosen, B. M.; Quasdorf, K. W.; Wilson, D. A.; Zhang, N.; Resmerita, A.M.; Garg, N. K.; Percec, V. Nickel-Catalyzed Cross-Couplings Involving Carbon-Oxygen Bonds. Chem. Rev. 2011, 111, 1346-1416. https://doi.org/10.1021/cr100259t.

(14) Li, B.-J.; Yu, D.-G.; Sun, C.-L.; Shi, Z.-J. Activation of "Inert" Alkenyl/Aryl $\mathrm{C}-\mathrm{O}$ Bond and Its Application in Cross-Coupling Reactions. Chem. Eur. J. 2011, 17, 1728-1759. https://doi.org/10.1002/chem.201002273.

(15) Mesganaw, T.; Garg, N. K. Ni- and Fe-Catalyzed Cross-Coupling Reactions of Phenol Derivatives. Org. Process Res. Dev. 2013, 17, 29-39. https://doi.org/10.1021/op300236f.
(16) Tobisu, M.; Chatani, N. Nickel-Catalyzed Cross-Coupling Reactions of Unreactive Phenolic Electrophiles via C-O Bond Activation. Top. Curr. Chem. 2016, 374, 41. https://doi.org/10.1007/s41061-016-0043-1.

(17) Takise, R.; Muto, K.; Yamaguchi, J. Cross-Coupling of Aromatic Esters and Amides. Chem. Soc. Rev. 2017, 46, 5864-5888. https://doi.org/10.1039/C7CS00182G.

(18) Guo, L.; Rueping, M. Decarbonylative Cross-Couplings: Nickel Catalyzed Functional Group Interconversion Strategies for the Construction of Complex Organic Molecules. Acc. Chem. Res. 2018, 51, 1185-1195. https://doi.org/10.1021/acs.accounts.8b00023.

(19) Qiu, Z.; Li, C.-J. Transformations of Less-Activated Phenols and Phenol Derivatives via C-O Cleavage. Chem. Rev. 2020, 120, 10454-10515. https://doi.org/10.1021/acs.chemrev.0c00088.

(20) Becica, J.; Leitch, D. C. C-O Bond Activation as a Strategy in PalladiumCatalyzed Cross-Coupling. Synlett 2021, 32, 641-646. https://doi.org/10.1055/a-1306-3228.

(21) Zheng, Y.-L.; Newman, S. G. Cross-Coupling Reactions with Esters, Aldehydes, and Alcohols. Chem. Commun. 2021, 57, 2591-2604. https://doi.org/10.1039/D0CC08389E.

(22) Zhao, B.; Prabagar, B.; Shi, Z. Modern Strategies for C-H Functionalization of Heteroarenes with Alternative Coupling Partners. Chem 2021. https://doi.org/10.1016/j.chempr.2021.08.001.

(23) Jin, W.; Yu, Z.; He, W.; Ye, W.; Xiao, W.-J. Efficient Rh(I)-Catalyzed Direct Arylation and Alkenylation of Arene $\mathrm{C}-\mathrm{H}$ Bonds via Decarbonylation of Benzoic and Cinnamic Anhydrides. Org. Lett. 2009, 11, 1317-1320. https://doi.org/10.1021/ol9000729.

(24) Pan, F.; Lei, Z.-Q.; Wang, H.; Li, H.; Sun, J.; Shi, Z.-J. Rhodium(I)-Catalyzed Redox-Economic Cross-Coupling of Carboxylic Acids with Arenes Directed by N-Containing Groups. Angew. Chem. Int. Ed. 2013, 52, 2063-2067. https://doi.org/10.1002/anie.201208362.

(25) Zhang, L.; Xue, X.; Xu, C.; Pan, Y.; Zhang, G.; Xu, L.; Li, H.; Shi, Z. Rhodium-Catalyzed Decarbonylative Direct C2-Arylation of Indoles with Aryl Carboxylic Acids. ChemCatChem 2014, 6, 3069-3074. https://doi.org/10.1002/cctc.201402534.

(26) Qiu, X.; Wang, P.; Wang, D.; Wang, M.; Yuan, Y.; Shi, Z. PIII-ChelationAssisted Indole C7-Arylation, Olefination, Methylation, and Acylation with Carboxylic Acids/Anhydrides by Rhodium Catalysis. Angew. Chem. Int Ed. 2019, 58, 1504-1508. https://doi.org/10.1002/anie.201813182.

(27) Zhang, L.; Qiu, R.; Xue, X.; Pan, Y.; Xu, C.; Wang, D.; Wang, X.; Xu, L.; $\mathrm{Li}, \mathrm{H}$. Rh(I)-Catalyzed Decarbonylative Direct C2-Olefination of Indoles with Vinyl Carboxylic Acids. Chem. Commun. 2014, 50, 12385-12388. https://doi.org/10.1039/C4CC06036A.

(28) Qiu, R.; Zhang, L.; Xu, C.; Pan, Y.; Pang, H.; Xu, L.; Li, H. RhodiumCatalyzed Decarbonylative Direct Olefination of Arenes with Vinyl Carboxylic Acids. Adv. Synth. Catal. 2015, 357, 1229-1236. https://doi.org/10.1002/adsc.201401020.

(29) Kwon, S.; Kang, D.; Hong, S. Rhl-Catalyzed Site-Selective Decarbonylative Alkenylation and Arylation of Quinolones under Chelation Assis tance. Eur. J. Org. Chem. 2015, 2015, 3671-3678. https://doi.org/10.1002/ejoc.201500187.

(30) Zhao, H.; Xu, J.; Xu, X.; Pan, Y.; Yu, Z.; Xu, L.; Fan, Q.; Walsh, P. J. $\mathrm{Rh}(\mathrm{I})$-Catalyzed Direct $\mathrm{C} 6-\mathrm{H}$ Arylation of 2-Pyridones with Aryl Carboxylic Acids. Adv. Synth. Catal. 2021, 363, 3995-4001. https://doi.org/10.1002/adsc.202100596.

(31) Amaike, K.; Muto, K.; Yamaguchi, J.; Itami, K. Decarbonylative C-H Coupling of Azoles and Aryl Esters: Unprecedented Nickel Catalysis and Application to the Synthesis of Muscoride A. J. Am. Chem. Soc. 2012, 134, 13573-13576. https://doi.org/10.1021/ja306062c.

(32) Liu, C.; Ji, C.-L.; Zhou, T.; Hong, X.; Szostak, M. Bimetallic Cooperative Catalysis for Decarbonylative Heteroarylation of Carboxylic Acids via CO/C-H Coupling. Angew. Chem. Int. Ed. 2021, 60, 10690-10699. https://doi.org/10.1002/anie.202100949.

(33) Xiang, K.; Zhang, S.; Liu, L.; Huang, T.; Tang, Z.; Li, C.; Xu, K.; Chen, T. Tunable C-H Arylation and Acylation of Azoles with Carboxylic Acids by $\mathrm{Pd} / \mathrm{Cu}$ Cooperative Catalysis. Org. Chem. Front. 2021, 8, 2543-2550. https://doi.org/10.1039/D1Q000380A.

(34) Muto, K.; Yamaguchi, J.; Itami, K. Nickel-Catalyzed C-H/C-O Coupling of Azoles with Phenol Derivatives. J. Am. Chem. Soc. 2012, 134, 169172. https://doi.org/10.1021/ja210249h. 
(35) Muto, K.; Yamaguchi, J.; Lei, A.; Itami, K. Isolation, Structure, and Reactivity of an Arylnickel(II) Pivalate Complex in Catalytic C-H/C-O Biary Coupling. J. Am. Chem. Soc. 2013, 135, 16384-16387. https://doi.org/10.1021/ja409803x.

(36) Meng, L.; Kamada, Y.; Muto, K.; Yamaguchi, J.; Itami, K. C-H Alkenylation of Azoles with Enols and Esters by Nickel Catalysis. Angew. Chem. Int. Ed. 2013, 52, 10048-10051. https://doi.org/10.1002/anie.201304492.

(37) Xu, H.; Muto, K.; Yamaguchi, J.; Zhao, C.; Itami, K.; Musaev, D. G. Key Mechanistic Features of Ni-Catalyzed C-H/C-O Biaryl Coupling of Azoles and Naphthalen-2-yl Pivalates. J. Am. Chem. Soc. 2014, 136 14834-14844. https://doi.org/10.1021/ja5071174.

(38) Muto, K.; Hatakeyama, T.; Yamaguchi, J.; Itami, K. C-H Arylation and Alkenylation of Imidazoles by Nickel Catalysis: Solvent-Accelerated Imidazole C-H Activation. Chem. Sci. 2015, 6, 6792-6798. https://doi.org/10.1039/C5SC02942B.

(39) Song, W.; Ackermann, L. Cobalt-Catalyzed Direct Arylation and Benzylation by $\mathrm{C}-\mathrm{H} / \mathrm{C}-\mathrm{O}$ Cleavage with Sulfamates, Carbamates, and Phosphates. Angew. Chem. Int. Ed. 2012, 51, 8251-8254. https://doi.org/10.1002/anie.201202466.

(40) Wang, Y.; Wu, S.-B.; Shi, W.-J.; Shi, Z.-J. C-O/C-H Coupling of Polyfluoroarenes with Aryl Carbamates by Cooperative Ni/Cu Catalysis. Org. Lett. 2016, 18, 2548-2551. https://doi.org/10.1021/acs.orglett.6b00819.

(41) Wang, T.-H.; Ambre, R.; Wang, Q.; Lee, W.-C.; Wang, P.-C.; Liu, Y.; Zhao, L.; Ong, T.-G. Nickel-Catalyzed Heteroarenes Cross Coupling via Tandem C-H/C-O Activation. ACS Catal. 2018, 8, 11368-11376. https://doi.org/10.1021/acscatal.8b03436.

(42) Toupalas, G.; Morandi, B. Non-Innocent Electrophiles Unlock Exogenous Base-Free Coupling Reactions. ChemRxiv 2021 https://doi.org/10.26434/chemrxiv.14217314.v1.

(43) Liégault, B.; Lapointe, D.; Caron, L.; Vlassova, A.; Fagnou, K. Establishment of Broadly Applicable Reaction Conditions for the Palladium-Catalyzed Direct Arylation of Heteroatom-Containing Aromatic Compounds. J. Org. Chem. 2009, 74, 1826-1834. https://doi.org/10.1021/j08026565.

(44) Lapointe, D.; Fagnou, K. Overview of the Mechanistic Work on the Concerted Metallation-Deprotonation Pathway. Chem. Lett. 2010, 39, 11181126. https://doi.org/10.1246/cl.2010.1118.

(45) Becica, J.; Gaube, G.; Sabbers, W. A.; Leitch, D. C. Oxidative Addition of Activated Aryl-Carboxylates to Pd(0): Divergent Reactivity Dependant on Temperature and Structure. Dalton Trans. 2020, 49, 16067-16071. https://doi.org/10.1039/D0DT01119C.

(46) Becica, J.; Heath, O. R. J.; Zheng, C. H. M.; Leitch, D. C. PalladiumCatalyzed Cross-Coupling of Alkenyl Carboxylates. Angew. Chem. Int. Ed. 2020, 59, 17277-17281. https://doi.org/10.1002/anie.202006586.

(47) Cox, P. A.; Leach, A. G.; Campbell, A. D.; Lloyd-Jones, G. C. Protodeboronation of Heteroaromatic, Vinyl, and Cyclopropyl Boronic Acids: $\mathrm{PH}-$ Rate Profiles, Autocatalysis, and Disproportionation. J. Am. Chem. Soc 2016, 138, 9145-9157. https://doi.org/10.1021/jacs.6b03283.

(48) Shevlin, M. Practical High-Throughput Experimentation for Chemists. ACS Med. Chem. Lett. 2017, 8, 601-607. https://doi.org/10.1021/acsmedchemlett.7b00165.

(49) Allen, C. L.; Leitch, D. C.; Anson, M. S.; Zajac, M. A. The Power and Accessibility of High-Throughput Methods for Catalysis Research. Na ture Catal. 2019, 2, 2-4. https://doi.org/10.1038/s41929-018-0220-4.

(50) Mennen, S. M.; Alhambra, C.; Allen, C. L.; Barberis, M.; Berritt, S.; Brandt, T. A.; Campbell, A. D.; Castañón, J.; Cherney, A. H.; Christensen, M.;
Damon, D. B.; Eugenio de Diego, J.; García-Cerrada, S.; García-Losada, P.; Haro, R.; Janey, J.; Leitch, D. C.; Li, L.; Liu, F.; Lobben, P. C.; MacMillan, D. W. C.; Magano, J.; McInturff, E.; Monfette, S.; Post, R. J.; Schultz, D.; Sitter, B. J.; Stevens, J. M.; Strambeanu, I. I.; Twilton, J.; Wang, K.; Zajac, M. A. The Evolution of High-Throughput Experimentation in Pharmaceutical Development and Perspectives on the Future. Org. Process Res. Dev. 2019, 23, 1213-1242. https://doi.org/10.1021/acs.oprd.9b00140.

(51) Isbrandt, E. S.; Sullivan, R. J.; Newman, S. G. High Throughput Strategies for the Discovery and Optimization of Catalytic Reactions. Angew. Chem. Int. Ed. 2019, 58, 7180-7191. https://doi.org/10.1002/anie.201812534

(52) Zalesskiy, S. S.; Ananikov, V. P. $\mathrm{Pd}_{2}(\mathrm{dba})_{3}$ as a Precursor of Soluble Metal Complexes and Nanoparticles: Determination of Palladium Active Species for Catalysis and Synthesis. Organometallics 2012, 31, 23022309. https://doi.org/10.1021/om201217r.

(53) Huang, J.; Isaac, M.; Watt, R.; Becica, J.; Dennis, E.; Saidaminov, M. I. Sabbers, W. A.; Leitch, D. C. DMPDAB-Pd-MAH: A Versatile Pd(0) Source for Precatalyst Formation, Reaction Screening, and PreparativeScale Synthesis. ACS Catal. 2021, 11, 5636-5646. https://doi.org/10.1021/acscatal.1c00288.

(54) Bates, C. M.; Bates, F. S. 50th Anniversary Perspective: Block Polymers-Pure Potential. Macromolecules 2017, 50, 3-22. https://doi.org/10.1021/acs.macromol.6b02355.

(55) Ji, Y.; Plata, R. E.; Regens, C. S.; Hay, M.; Schmidt, M.; Razler, T.; Qu Y.; Geng, P.; Hsiao, Y.; Rosner, T.; Eastgate, M. D.; Blackmond, D. G. Mono-Oxidation of Bidentate Bis-Phosphines in Catalyst Activation: Kinetic and Mechanistic Studies of a Pd/Xantphos-Catalyzed C-H Functionalization. J. Am. Chem. Soc. 2015, 137, 13272-13281. https://doi.org/10.1021/jacs.5b01913.

(56) Gaube, G.; Pipaon-Fernandez, N.; Leitch, D. C. An Evaluation of Palladium-Based Catalysts for the Base-Free Borylation of Alkenyl Carboxylates. ChemRxiv 2021. https://doi.org/10.33774/chemrxiv-2021-x0h4mv2.

(57) Flynn, A. B.; Ogilvie, W. W. Stereocontrolled Synthesis of Tetrasubstituted Olefins. Chem. Rev. 2007, 107, 4698-4745. https://doi.org/10.1021/cr050051k.

(58) Polák, P.; Váňová, H.; Dvořák, D.; Tobrman, T. Recent Progress in Transition Metal-Catalyzed Stereoselective Synthesis of Acyclic All-Carbon Tetrasubstituted Alkenes. Tet. Lett. 2016, 57, 3684-3693. https://doi.org/10.1016/j.tetlet.2016.07.030.

(59) Caruano, J.; Muccioli, G. G.; Robiette, R. Biologically Active Y-Lactams: Synthesis and Natural Sources. Org. Biomol. Chem. 2016, 14, 1013410156. https://doi.org/10.1039/C6OB01349J.

(60) Chatterjee, S.; Sahoo, R.; Nanda, S. Recent Reports on the Synthesis of Y-Butenolide, $\mathrm{y}$-Alkylidenebutenolide Frameworks, and Related Natural Products. Org. Biomol. Chem. 2021, 19, 7298-7332. https://doi.org/10.1039/D1OB00875G.

(61) Nauen, R.; Jeschke, P.; Velten, R.; Beck, M. E.; Ebbinghaus-Kintscher U.; Thielert, W.; Wölfel, K.; Haas, M.; Kunz, K.; Raupach, G. Flupyradifurone: A Brief Profile of a New Butenolide Insecticide. Pest Management Science 2015, 71, 850-862. https://doi.org/10.1002/ps.3932.

(62) Rattray, B.; Nugent, D. J.; Young, G. Rofecoxib as Adjunctive Therapy for Haemophilic Arthropathy. Haemophilia 2005, 11, 240-244. https://doi.org/10.1111/j.1365-2516.2005.01087.x. 